ARTICLE

\title{
Detection of the thietane precursor in the UVA formation of the DNA 6-4 photoadduct
}

\author{
Luis A. Ortiz-Rodríguez (1) ${ }^{1}$, Christian Reichardt ${ }^{1,3}$, Sean J. Hoehn (10) ${ }^{1,3}$, Steffen Jockusch (1) ${ }^{2} \&$
} Carlos E. Crespo-Hernández (1) ${ }^{1 凶}$

Notwithstanding the central biological role of the (6-4) photoadduct in the induction of skin cancer by sunlight, crucial mechanistic details about its formation have evaded characterization despite efforts spanning more than half a century. 4-Thiothymidine (4tT) has been widely used as an important model system to study its mechanism of formation, but the excited-state precursor, the intermediate species, and the time scale leading to the formation of the (6-4) photoadduct have remained elusive. Herein, steady-state and time-resolved spectroscopic techniques are combined with new and reported quantum-chemical calculations to demonstrate the excited state leading to the formation of the thietane intermediate, its rate, and the formation of the (6-4) photoadduct using the $5^{\prime}-\mathrm{TT}(4 \mathrm{tT}) \mathrm{T}(4 \mathrm{tT}) \mathrm{TT}-\mathrm{3}^{\prime}$ DNA oligonucleotide. Efficient, sub-1 ps intersystem crossing leads to the population of a triplet minimum of the thietane intermediate in as short as 3 ps, which intersystem crosses to its ground state and rearranges to form the (6-4) photoadduct.

\footnotetext{
${ }^{1}$ Department of Chemistry, Case Western Reserve University, Cleveland, OH 44106, USA. ${ }^{2}$ Department of Chemistry, Columbia University, New York, NY 10027, USA. ${ }^{3}$ These authors contributed equally: Christian Reichardt, Sean J. Hoehn. ${ }^{\bowtie}$ email: carlos.crespo@case.edu
} 
T he cis-syn cyclobutane dimers and the (6-4) pyrimidinepyrimidinone adducts are the most frequent photolesions occurring at bipyrimidine sites in DNA of all forms of life $\mathrm{e}^{1,2}$ following exposure to ultraviolet (UV) solar radiation ${ }^{1,3-6}$. In particular, the (6-4) photoadducts hold a pyri-midinone chromophore within, which can act as an internal photosensitizer to form additional cyclobutane dimers in $\mathrm{DNA}^{7,8}$ or can absorb UVA/UVB radiation to form Dewar valence isomers ${ }^{1,2,9}$.

Despite more than six decades of focused effort in the field, there is still substantial debate regarding the excited state, leading to the formation of the (6-4) photoadducts, as well as, a complete lack of information regarding the timescales at which the oxetane, azetidine, and thietane intermediates are formed ${ }^{1,2,10}$. Indeed, as depicted in Fig. 1 for the oxetane intermediate, the ${ }^{1} n \pi^{*},{ }^{3} n \pi^{*}$, ${ }^{3} \pi \pi^{*}$, and charge-transfer singlet and triplet states have all been proposed as precursor states in the formation of these elusive intermediates $2,4,5,10-27$. Early investigations suggested that the (6-4) photoadducts may have originated from excited singlet states because triplet photosensitization did not lead to the formation of these photoadducts, and triplet quenchers did not prevent their formation $^{3-5,28}$. Recent theoretical investigations have presented conflicting predictions with several groups providing evidence for the participation of excited triplet states in the formation of the oxetane and azetidine intermediates ${ }^{14,15,18,21}$, while others substantiate participation of charge-transfer states of either triplet or singlet multiplicity 12,17,19,29-32. The participation of an electron transfer pathway in the formation of the oxetane intermediate was proposed recently using experimental and computational investigations for a thymine-thymine dinucleotide analog in which the 5'thymine was replaced by a meta-xylene moiety ${ }^{33}$. This work demonstrates that $5^{\prime} \rightarrow 3$ ' electron transfer is a necessary first step in the formation of the xylene-thymine (6-4) photoadduct analog. However, the authors were unable to experimentally detect the oxetane intermediate ${ }^{33}$, and only computational predictions supported its participation in the formation of the (6-4) photoadduct in the xylene-thymine dinucleotide. Furthermore, the redox properties of meta-xylene are significantly different from those of thymine, favoring a complete electron transfer pathway in this dinucleotide analog ${ }^{33}$ relative to a partial charge-transfer pathway thymine-thymine dinucleotide ${ }^{18-20}$.

The 4-thiothymidine-thymine dinucleotide is an important model system that has been widely used to study and understand the mechanism of formation of the (6-4) photoadduct in $\mathrm{DNA}^{27,34-38}$. Furthermore, to the best of our knowledge, thietane is the only intermediate that has been characterized spectroscopically at room temperature ${ }^{34}$. This dinucleotide analogue is based on the photochemistry of 4-thiothymidine (4tT), in which the oxygen atom at the $\mathrm{C} 4$ position of the $3^{\prime}$-thymine moiety is substituted by a sulfur atom. This single-atom substitution shifts the absorption spectrum of thymidine to lower energies, allowing for the selective excitation of $4 \mathrm{tT}$ with UVA radiation when incorporated in DNA dinucleotide and oligonucleotide systems ${ }^{34,37}$. Importantly, UVA excitation of $4 \mathrm{tT}$-containing oligonucleotides results in the formation of the $S^{5}-(6-4)$ photoadduct analog of the natural (6-4) photoadduct, without the competitive formation of the $[2+2]$ cyclobutane thymidine dimer observed in $\mathrm{DNA}^{34,37}$. However, despite of the wide use of the thietane intermediate as a stable substrate analog of the oxetane intermediate in $\mathrm{DNA}^{34,36,37,39}$ and $\mathrm{RNA}^{25,26,40,41}$ systems, crucial mechanistic information is still lacking, such as the excited-state precursor and the timescale leading to its formation.

In this contribution, steady-state absorption and emission spectroscopic techniques, time-resolved luminescence spectroscopy, femtosecond broadband transient absorption, and time-dependent density functional (TDDFT) calculations are combined to reveal the excited state leading to the formation of the thietane intermediate, its rate of formation, as well as the subsequent formation of the (6-4) photoadduct in DNA. A 7-mer singlestranded DNA oligonucleotide containing two pairs of adjacent 4-thiothymidine-thymidine nucleotides (4tTT), 5'-TT(4tT)T(4tT) TT- $3^{\prime}$, referred to as $\mathrm{T}(\mathrm{T} 4 \mathrm{tT})_{2} \mathrm{~T}_{2}$, hereafter, is investigated in phosphate buffered saline (PBS) solution at $\mathrm{pH}$ 7.4. For comparison, consecutive experiments are performed using $4 \mathrm{t} T$ nucleoside under equal experimental conditions, because its photophysics and excited-state dynamics are now well established ${ }^{42-51}$. It is shown that efficient, sub-1 ps intersystem crossing occurs in this singlestranded DNA oligonucleotide, leading to the population of a triplet-state minimum of the thietane intermediate in a time delay as short as 3 ps ( $\tau=290 \pm 70 \mathrm{ps}$ ) in $25 \pm 5 \%$ yield from two separate measurements. The triplet-state minimum of the thietane intersystem crosses to the ground state of the thietane intermediate and then rearranges to form the characteristic (6-4) photoadduct. A fraction of the triplet-state population in the oligonucleotide that is not conducive to (6-4) photoadduct formation, decays back to the ground state in ca. 23 ns-two order of magnitude faster that triplet decay in the $4 \mathrm{tT}$ monomer ${ }^{42}$. Furthermore, it is shown that the quantum yield of singlet oxygen generation in $\mathrm{T}(\mathrm{T} 4 \mathrm{tT})_{2} \mathrm{~T}_{2}$ is $88 \%$ lower than in the $4 \mathrm{tT}$ monomer under equal experimental conditions.

\section{Results}

Steady-state absorption and emission spectra. Figure 2 shows the steady-state absorption and emission spectra of $\mathrm{T}(\mathrm{T} 4 \mathrm{tT})_{2} \mathrm{~T}_{2}$ and $4 \mathrm{tT}$ in PBS pH 7.4 at room temperature. Both $\mathrm{T}(\mathrm{T} 4 \mathrm{tT})_{2} \mathrm{~T}_{2}$ and $4 \mathrm{tT}$ exhibit a low-energy absorption band with maximum at

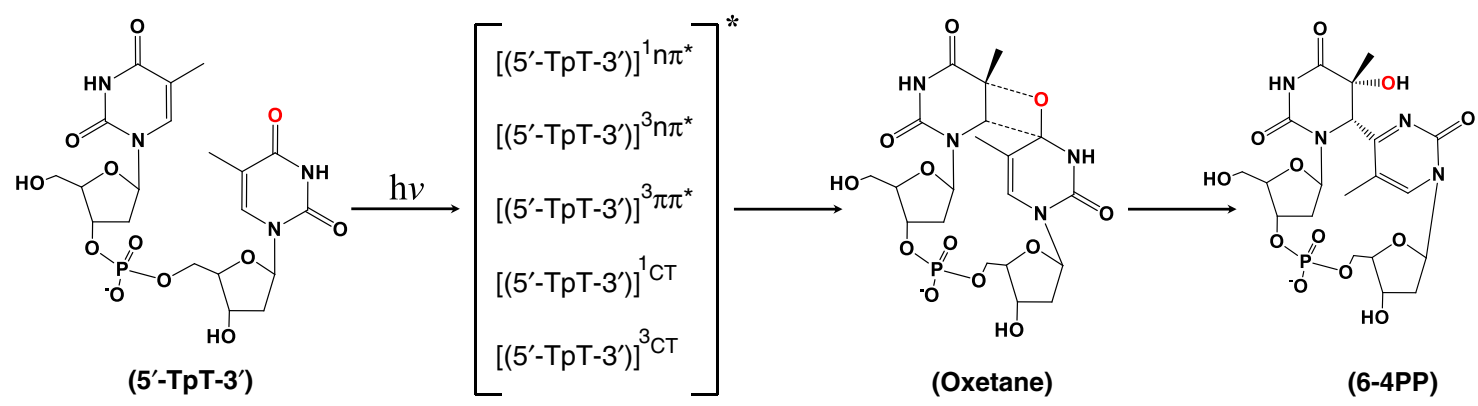

Fig. 1 Literature-proposed excited-state precursors of the oxetane intermediate $2-5,10-21,28.5 '-T p T-3^{\prime}$ represents a thymine-thymine DNA dinucleotide, while 6-4PP represents the final (6-4) pyrimidine-pyrimidinone adduct formed after DNA absorbs ultraviolet radiation. The 5'-TpT-3' structure was chosen as a representative DNA structure for simplicity with the purpose of highlighting that two thymidine bases need to be close to each other for the reaction to occur. This figure does not imply that the reaction is limited to a dinucleotide, but it can also occur in single- and double-stranded oligonucleotides. The oxygen atom involved in the initial $[2+2]$ cycloaddition reaction is highlighted with red color. CT stands for charge transfer. 


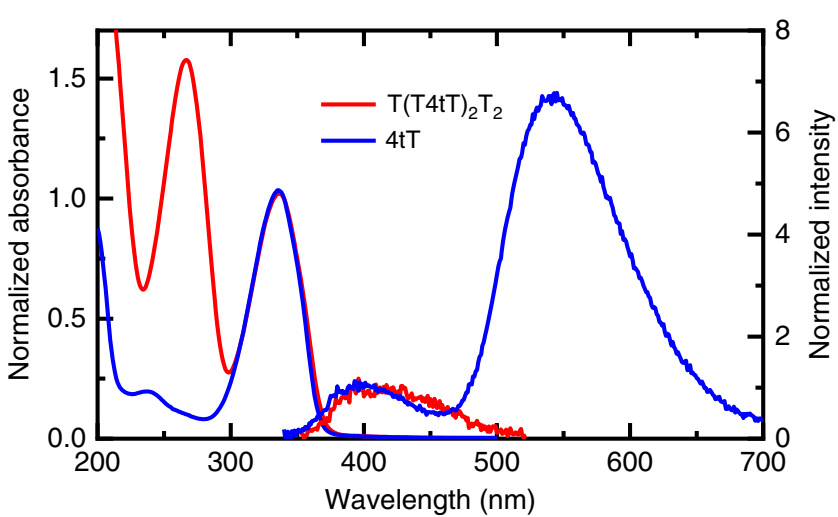

Fig. 2 Normalized absorption and emission spectra for $4 t T$ and $T$

$(\mathbf{T 4 t T})_{\mathbf{2}} \mathbf{T}_{\mathbf{2}}$. Room-temperature absorption and emission spectra for $4 \mathrm{tT}$ in $\mathrm{PBS}$ at $\mathrm{pH} 7.4$ are shown using blue lines, while those for $\mathrm{T}(\mathrm{T} 4 \mathrm{tT})_{2} \mathrm{~T}_{2}$ are depicted using red lines. We remark that the emission spectrum for $\mathrm{T}(\mathrm{T} 4 \mathrm{tT})_{2} \mathrm{~T}_{2}$ has a very small intensity and may not be measured accurately within the sensitivity of the spectrofluorometer used in this work.

Photoexcitation was performed at $340 \mathrm{~nm}$.

ca. $336 \mathrm{~nm}$, which is slightly red shifted in $\mathrm{T}(\mathrm{T} 4 \mathrm{tT})_{2} \mathrm{~T}_{2}$ compared with $4 \mathrm{tT}$. In addition, the absorption spectrum of $\mathrm{T}(\mathrm{T} 4 \mathrm{tT})_{2} \mathrm{~T}_{2}$ shows a high-energy band centered at $266 \mathrm{~nm}$, whereas the $4 \mathrm{tT}$ monomer shows a similar band at $237 \mathrm{~nm}$ that has significantly lower intensity. The band at $266 \mathrm{~nm}$ is primarily due to the absorption by the thymidine nucleotides in the $\mathrm{T}(\mathrm{T} 4 \mathrm{tT})_{2} \mathrm{~T}_{2}$ oligonucleotide, whereas it is due to a $S_{0} \rightarrow S_{n}$ transition in the $4 \mathrm{tT}$ monomer ${ }^{48}$. Intriguingly, while both fluorescence $(\sim 400 \mathrm{~nm})$ and phosphorescence $(\sim 540 \mathrm{~nm})$ emission are observed for the $4 \mathrm{tT}$ monomer in aqueous solution (Fig. 2) ${ }^{44}$, no detectable phosphorescence is observed for $\mathrm{T}(\mathrm{T} 4 \mathrm{tT})_{2} \mathrm{~T}_{2}$, and only a negligibly small fluorescence-emission band is observed, which could not be accurately measured within the sensitivity of the spectrofluorometer used. The lack of phosphorescence emission in the oligonucleotide suggests a significant quenching of the near-unity triplet yield reported for the $4 \mathrm{tT}$ monomer ${ }^{42,44}$ in solution that occurs when $4 \mathrm{tT}$ is incorporated in the single-stranded DNA oligonucleotide.

Determination of quantum yields of singlet-oxygen generation. To further investigate the proposed triplet quenching of $4 \mathrm{tT}$ in $\mathrm{T}(\mathrm{T} 4 \mathrm{tT})_{2} \mathrm{~T}_{2}$, the nglet-oxygen quantum yield of both $4 \mathrm{tT}$ and $\mathrm{T}(\mathrm{T} 4 \mathrm{tT})_{2} \mathrm{~T}_{2}$ were measured under equal conditions using timeresolved phosphorescence spectroscopy. The singlet-oxygen phosphorescence signals were obtained in deuterated TRIS buf-

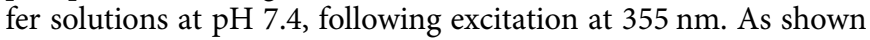
in Fig. 3, a significant decrease in the intensity of the singletoxygen phosphorescence signal is observed for $\mathrm{T}(\mathrm{T} 4 \mathrm{t} \mathrm{T})_{2} \mathrm{~T}_{2}$ under both $\mathrm{O}_{2}$ and air-saturated conditions compared with $4 \mathrm{tT}$ under air-saturated conditions. Indeed, nearly an order of magnitude reduction in singlet-oxygen quantum yield was measured for $\mathrm{T}$ $(\mathrm{T} 4 \mathrm{tT})_{2} \mathrm{~T}_{2}$ relative to $4 \mathrm{tT}$ (Table 1 ). The $88 \%$ decrease in the singlet-oxygen yield lend further support to the idea that the incorporation of $4 \mathrm{tT}$ in DNA results in a significant quenching of the excited triplet-state population.

Ultrafast triplet-state dynamics. Femtosecond broadband transient-absorption spectroscopy was used to directly probe the excited-states dynamics of both $4 \mathrm{tT}$ and $\mathrm{T}(\mathrm{T} 4 \mathrm{tT})_{2} \mathrm{~T}_{2}$ following excitation at $342 \mathrm{~nm}$ in PBS solutions at $\mathrm{pH}$ 7.4. Figure 4 compares the transient-absorption spectra of both $4 \mathrm{tT}$ and $\mathrm{T}(\mathrm{T} 4 \mathrm{t} \mathrm{T})_{2} \mathrm{~T}_{2}$, which were measured consecutively under equal experimental conditions. The multidimensional transient data were globally fitted using a four-component sequential kinetic model, where the fourth kinetic component required a large lifetime to satisfactorily fit the long-lived transient signals of both $\mathrm{T}(\mathrm{T} 4 \mathrm{tT})_{2} \mathrm{~T}_{2}$ and $4 \mathrm{tT}$. As can be seen in Fig. 4, the long-lived transient signal of both $\mathrm{T}(\mathrm{T} 4 \mathrm{tT})_{2} \mathrm{~T}_{2}$ and $4 \mathrm{tT}$ last beyond the $3 \mathrm{~ns}$ time window of our femtosecond spectrometer. Representative kinetic traces and best global fit curves are shown in Fig. 5, while the associated lifetimes are collected in Table 1. The evolutionassociated difference spectra (EADS) extracted from global and target analyses of the transient data for the monomer and the single-stranded oligonucleotide are shown in Supplementary Figs. 1 and 2, respectively. The initial lifetime for the $4 \mathrm{tT}$ nucleoside is in good agreement with that reported earlier ${ }^{44,48}$. The second and third lifetimes of $4 \mathrm{t} \mathrm{T}$ are associated to vibrational relaxation in the triplet state and fractional triplet self-quenching due to aggregate formation $44,45,48$. Hence, their magnitudes are expected to depend on both the ground-state concentration of $4 \mathrm{tT}$ and the experimental conditions used.

\section{Discussion}

As can be seeing on the top panel of Fig. 4, the initial ca. sub-1 ps dynamics for both the monomer and the single-stranded DNA oligonucleotide are essentially the same. The dynamics are characterized by three primary bands-two with negative amplitude ( $<365 \mathrm{~nm}$ and from ca. 365 to $500 \mathrm{~nm}$ ) and one with positive amplitude (ca. $>500 \mathrm{~nm}$ ) - the positive-amplitude band in the visible rising and shifting to the blue within a 1 ps time delay (Fig. 4a, d). These bands are assigned to ground-state depopulation, stimulated emission, and sub-1 ps intersystem crossing leading to the population of the lowest-energy triplet state $\left(\mathrm{T}_{1}\right)$, respectively, in agreement with previous experimental observations for the $4 \mathrm{tT}$ monomer ${ }^{43-45,48}$. Significantly, the femtosecond transient-absorption experiments demonstrate that ultrafast intersystem crossing dynamics to populate the $T_{1}$ state also occurs in the single-stranded DNA containing 4tT. To the best of our knowledge, this is the first experimental evidence of ultrafast (i.e., within $\tau_{1}=0.26 \pm 0.02 \mathrm{ps}$ ) and efficient triplet-state population reported for a single-stranded DNA oligonucleotide. This experimental result is fully supported by high-level quantum-chemical calculations performed recently for a doublestranded DNA oligonucleotide containing $4 \mathrm{tT}^{23}$, which predictions are discussed in more detail below.

Next, we devote particular attention to both the dynamics and the spectral changes observed in the triplet absorption spectrum from ca. 380 to $670 \mathrm{~nm}$. Panels b and e in Fig. 4 show the initial decay dynamics of the $\mathrm{T}_{1}$ state of $4 \mathrm{tT}$ as a monomer and when incorporated adjacent to thymine bases in the singlestranded DNA, respectively. Significant spectral and dynamical differences are observed between $4 \mathrm{tT}$ and $\mathrm{T}(\mathrm{T} 4 \mathrm{tT})_{2} \mathrm{~T}_{2}$ during the time window from ca. 1 to 65 ps and beyond, specifically in the spectral region from ca. 380 to $500 \mathrm{~nm}$. While the intensity in the spectral region from 380 to $450 \mathrm{~nm}$ decreases with an increase in time delay for $4 \mathrm{tT}$, the intensity in the spectral region from 380 to $495 \mathrm{~nm}$ actually increases for $\mathrm{T}(\mathrm{T} 4 \mathrm{tT})_{2} \mathrm{~T}_{2}$ (Fig. 4b, e). Furthermore, an apparent isosbestic point is observed at ca. $495 \mathrm{~nm}$ in the oligonucleotide (not observed in the monomer), which is indicative of a state-to-state process. Conversely, the intensity of the lower-energy triplet band at $565 \mathrm{~nm}$ shifts to $550 \mathrm{~nm}$ and slightly decreases during the time window between ca. 1 to 5 ps in both samples. Once the triplet band shits to $550 \mathrm{~nm}$, it continues to decay in both the monomer and the single-stranded oligonucleotide. The result in Fig. $4 \mathrm{c}$ that the triplet state of $4 \mathrm{tT}$ continues to decay monotonically in hundreds of nanoseconds, is in good agreement with previous observations ${ }^{42,50}$. Supplementary Fig. 3 shows 
that the dynamics of the transient-absorption bands $\sim 430$ and $550 \mathrm{~nm}$ are quite different in the monomer compared to the single-stranded DNA oligonucleotide. The blue shift observed in the transient spectra during the ca. 1 to 5 ps time window is associated with vibrational relaxation in the triplet state of $4 \mathrm{tT}$ in both the monomer and the single-stranded oligonucleotide $\left(\tau_{2}\right.$ in Table 1$)$. In addition, a small fraction (ca. $30 \pm 5 \%$ ) of the triplet-state population in the $4 \mathrm{tT}$ monomer decays by triplet self-quenching ${ }^{44,45}$ to the ground state with a lifetime of $56 \pm 8$ ps under the experimental conditions used.

Returning to the dynamics in the single-stranded DNA oligonucleotide, the data presented in panels $\mathrm{e}$ and $\mathrm{f}$ of Fig. 4 demonstrate that at least two different transient species are participating in the dynamics during the time window from ca. 1 ps to $3 \mathrm{~ns}$. While the transient spectra in the spectral region from ca. 380 to $460 \mathrm{~nm}$ continues to growth for up to ca. $1 \mathrm{~ns}$, the transient-absorption band with maximum at $550 \mathrm{~nm}$ decays during the same time window. On the one hand, we assign the decrease of the $550 \mathrm{~nm}$ absorption band as due to a large fraction of the triplet state of $4 \mathrm{tT}$ in the oligonucleotide decaying nonradiatively to the ground state, which we estimate to occur in ca. $23 \mathrm{~ns}\left(\tau_{4}\right)$, assuming triplet self-quenching of $4 \mathrm{tT}$ with adjacent thymine bases that is not conducive to reaction. Absorption spectra recorded before and after the laser experiments support the idea that a large fraction of the photoexcited $4 \mathrm{tT}$ in the oligonucleotide decays back to the ground state (Supplementary Fig. 4a). On the other hand, the transient species increasing in the spectral region from ca. 380 to $460 \mathrm{~nm}$ is assigned to the population of a triplet-state minimum of the thietane intermediate (Fig. 6), which is populated from the interaction of the triplet

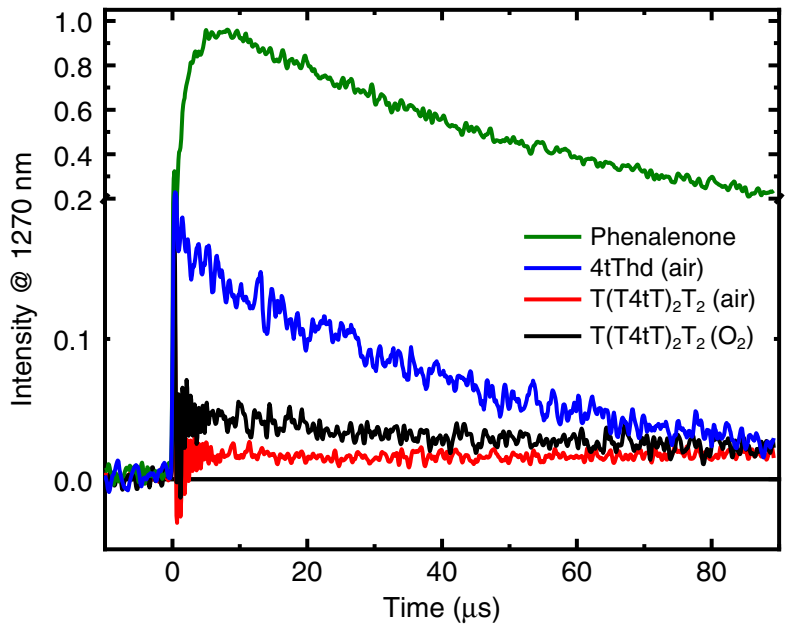

Fig. 3 Time-resolved phosphorescence signals at $1270 \mathbf{n m}$. Singlet-oxygen decay traces were generated by pulsed photoexcitation $(355 \mathrm{~nm}, 7 \mathrm{~ns}$ pulses) of $4 \mathrm{tT}$ (blue line), $\mathrm{T}(\mathrm{T} 4 \mathrm{tT})_{2} \mathrm{~T}_{2}$ (red and black lines), and phenalenone (green line, $\left.\Phi_{\Delta}=0.98\right)^{52}$ in $\mathrm{O}_{2}$ (black line) and air-saturated (blue and red lines) TRIS-buffered $\mathrm{D}_{2} \mathrm{O}$ solution. state of $4 \mathrm{tT}$ with the adjacent $5^{\prime}$-thymine base in the oligonucleotide. Using Eq. 1 and the results from the global fit analysis, a relative quantum yield of $25 \pm 5 \%$ was estimated from two separate measurements for the population of the triplet-state minimum of the thietane intermediate. This value is larger than the quantum yield reported by Warren et al. ${ }^{37}$ of $10 \%$ for the thietane intermediate in a double-stranded oligonucleotide containing one $4 \mathrm{tT}$. This suggests that a fraction of the triplet-state minimum of the thietane intersystem crosses to populate the thietane intermediate in the ground state (Fig. 6), while another fraction is not conducive to the formation of the thietane intermediate in the ground state. This result is not necessarily surprising because the $4 \mathrm{tT}$ in the single-stranded oligonucleotide can explore a larger conformational space (such as unstacked and stacked conformations) than when it is incorporated in doublestranded oligonucleotides.

Interestingly, the amplitude of the triplet-state minimum of the thietane at $430 \mathrm{~nm}$ increases from a time delay of ca. 3 ps to up to $1 \mathrm{~ns}$ (see Fig. 5b). This suggests that the triplet minimum of the thietane begins to populate in ca. 3 ps, while intersystem crossing from the triplet minimum of the thietane to the thietane intermediate in the ground state occurs on a longer timescale than 3 ns. Attempts to measure the rate of intersystem crossing to the thietane intermediate in the ground state were unsuccessful because of the limited white light generation below $420 \mathrm{~nm}$ of the nanosecond transient-absorption spectrometer available to us ${ }^{53}$. This is consistent with TDDFT calculations reported in the Supplementary Information, which suggest that the thietane intermediate in the ground state absorbs at wavelengths shorter than $300 \mathrm{~nm}$ (Supplementary Fig. 5). Similarly, we were unable to measure the intersystem crossing from the triplet minimum of the thietane to the thietane intermediate in the ground state, nor the triplet decay lifetime of $4 \mathrm{tT}$ in the oligonucleotide, because of the low sensitivity of our nanosecond spectrometer ${ }^{53,54}$. While this is a disappointing result, it lends further support to the idea that most, if not all, of the triplet state of $4 \mathrm{tT}$ in the oligonucleotide that is not conducive to thietane formation decays to the ground state in tens of nanoseconds, as the global and target analysis of the data suggest. A probable quenching mechanism is triplet self-quenching with an adjacent thymine base.

Recent CASPT2 quantum-chemical and molecular dynamics simulations that include explicit solvent effects have been performed $^{23}$, which further support the assignment of the transient species in the spectral region from 380 to $460 \mathrm{~nm}$ to the triplet minimum of a thietane intermediate (see Fig. 6). Specifically, Xie and Cui presented a theoretical investigation that provides crucial mechanistic information about the photochemical reaction of the T4tT bipyrimidine sequence in a double-stranded $5^{\prime}$-ACCT4tT CGC- $3^{\prime} \cdot 3^{\prime}$-TGGAAGCG-5' DNA oligonucleotide ${ }^{23}$. The authors identified five efficient nonadiabatic relaxation pathways starting from the initially populated ${ }^{1} \pi \pi^{*}\left(\mathrm{~S}_{2}\right)$ state of the T4tT sequence, which populate the $\mathrm{T}_{1}$ state of $4 \mathrm{tT}$. These nonadiabatic decay pathways involve two- and four-state intersection crossings, which the authors labeled as $\mathrm{S}_{2} / \mathrm{S}_{1}$ and $\mathrm{S}_{2} / \mathrm{T}_{2} / \mathrm{S}_{1} / \mathrm{T}_{1}$, respectively ${ }^{23}$,

Table 1 Transient-absorption lifetimes and quantum yields of singlet-oxygen generation.

\begin{tabular}{|c|c|c|c|c|c|c|}
\hline DNA system & $\tau_{1}(\mathrm{ps})^{\mathrm{a}}$ & $\tau_{2}(\mathrm{ps})^{\mathrm{a}}$ & $\tau_{3}(\mathrm{ps})^{\mathrm{a}}$ & $\tau_{4}$ (ns) & $\Phi_{\Delta}$ (air) $^{b}$ & $\Phi_{\Delta}\left(\mathrm{O}_{2}\right)^{b}$ \\
\hline $\mathrm{T}(\mathrm{T} 4 \mathrm{tT})_{2} \mathrm{~T}_{2}$ & $0.26 \pm 0.02$ & $3 \pm 2^{c}$ & $290 \pm 70^{c}$ & $23^{\mathrm{a}, \mathrm{d}}$ & $0.02 \pm 0.01$ & $0.04 \pm 0.01$ \\
\hline $4 \mathrm{tT}$ & $0.24 \pm 0.02$ & $2 \pm 1^{c}$ & $56 \pm 8^{c}$ & $4200 \pm 300^{e}$ & $0.17 \pm 0.02$ & - \\
\hline
\end{tabular}

aMeasured in PBS pH 7.4 following excitation at $342 \mathrm{~nm}$ with reported errors equal to twice the standard deviation of at least two separate measurements.

bMeasured in deuterated TRIS buffer solutions at $\mathrm{pH} 7.4$ following excitation at $355 \mathrm{~nm}$.

$\tau_{\tau_{2}}$ and $\tau_{3}$ are correlated to each other, and the reported large errors take into consideration this correlation.

dExtrapolated lifetime assuming a complete exponential decay to the ground state.

eTriplet lifetime calculated at infinite dilution in acetonitrile ${ }^{42}$ 
in good agreement with analogous calculations done for the $4 \mathrm{tT}$ monomer in solution ${ }^{48}$. Furthermore, the calculations predicted high-energy barriers between both the $S_{1}$ state and the ground state $\left(\mathrm{S}_{0}\right)$, and between the $\mathrm{T}_{1}$ and the $\mathrm{S}_{0}$ states $^{23}$. The results shown in Fig. 4 are in agreement with such high energy barriers, evidencing ultrafast and efficient population of the triplet state of $4 \mathrm{tT}$ in high yield in the $\mathrm{T}(\mathrm{T} 4 \mathrm{tT})_{2} \mathrm{~T}_{2}$ single-stranded DNA oligonucleotide. This hypothesis is further supported by the prediction of large spin-orbit couplings between the $\mathrm{S}_{1} / \mathrm{T}_{1}$ and $\mathrm{S}_{1} / \mathrm{T}_{2}$ crossing structures of 94.1 and $69.2 \mathrm{~cm}^{-1}$, respectively ${ }^{23}$, leading to the efficient and ultrafast population of the $\mathrm{T}_{1}$ state of $4 \mathrm{tT}$ through a $\mathrm{T}_{2} / \mathrm{T}_{1}$ conical intersection in the double-stranded DNA oligonucleotide.

After reaching the $\mathrm{T}_{1}$ state of $4 \mathrm{t} \mathrm{T}$ in the oligonucleotide, the calculations predict that a $[2+2]$ cycloaddition reaction takes place leading to the population of a thietane triplet minimum,

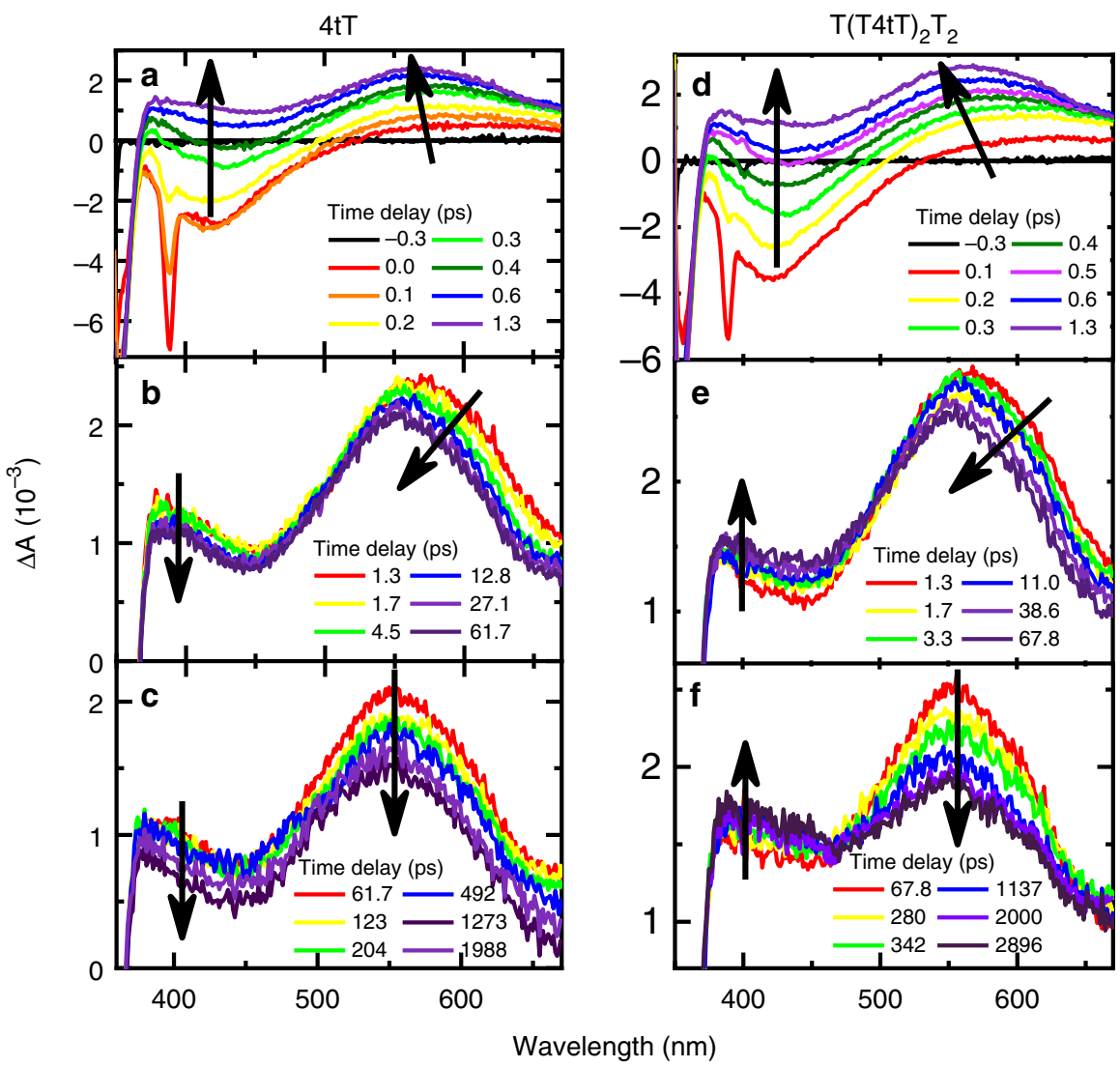

Fig. 4 Broadband transient-absorption spectra for $\mathbf{4 t T}$ and $\mathbf{T}\left(\mathbf{T 4 t T} \mathbf{~} \mathbf{2}_{\mathbf{2}} \mathbf{T}_{\mathbf{2}}\right.$. Left panel (i.e., a-c) depicts the transient data for the $4 \mathrm{tT}$ nucleoside, while the right panel (i.e., d-f) shows the transient data for $\mathrm{T}(\mathrm{T} 4 \mathrm{tT})_{2} \mathrm{~T}_{2}$ both in PBS pH 7.4 upon excitation at $342 \mathrm{~nm}$. Stimulated Raman emission from the water solvent is observed at $385 \mathrm{~nm}$ within the cross-correlation of the pump and probe beams in both data sets (i.e., panels a and $\mathbf{d}$ ), and its maximum amplitude was used to define the time delay equal to zero picoseconds. The transient-absorption spectra are represented with solid lines using a rainbow of colors. Black arrows indicate the transition of the absorption bands as a function of time delay and are used as a guide to the eye.
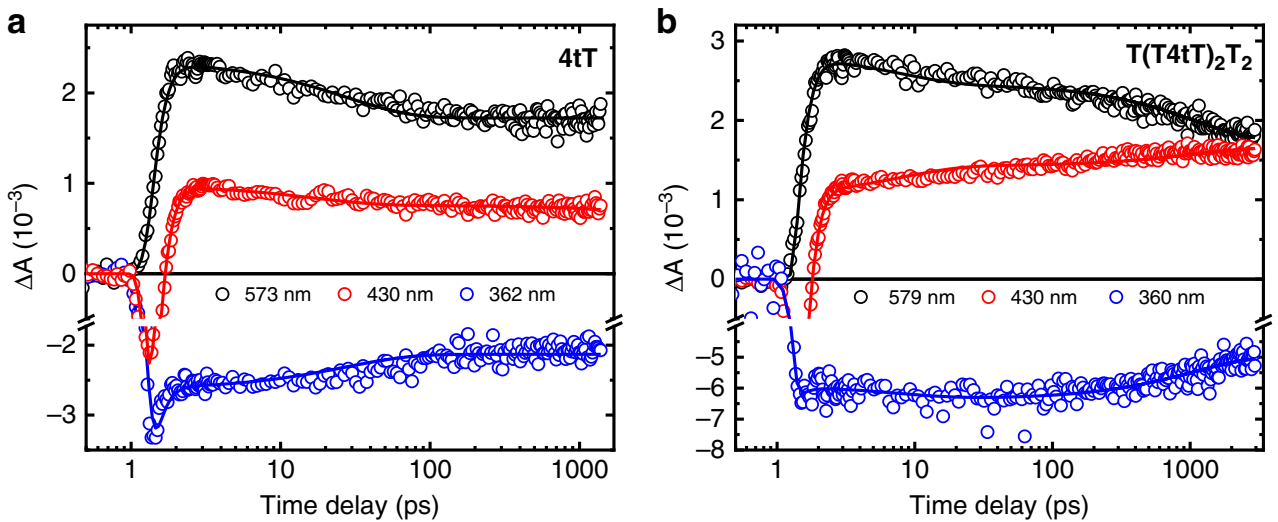

Fig. 5 Representative kinetic traces and fits at three probe wavelengths. Panel a shows kinetic traces for $4 \mathrm{tT}$ at the probe wavelengths of $573 \mathrm{~nm}$ (black), $430 \mathrm{~nm}$ (red), and $362 \mathrm{~nm}$ (blue), while panel $\mathbf{b}$ depicts kinetic traces for $\mathrm{T}(\mathrm{T} 4 \mathrm{tT})_{2} \mathrm{~T}_{2}$ at the probe wavelengths of $579 \mathrm{~nm}$ (black), $430 \mathrm{~nm}$ (red), and 360 $\mathrm{nm}$ (blue). Both samples were dissolved in PBS solvent at pH 7.4 and excited at $340 \mathrm{~nm}$. The raw data are represented with open circles, while the lines represent the best fits obtained from global and target analyses to the multidimensional transient-absorption data. 


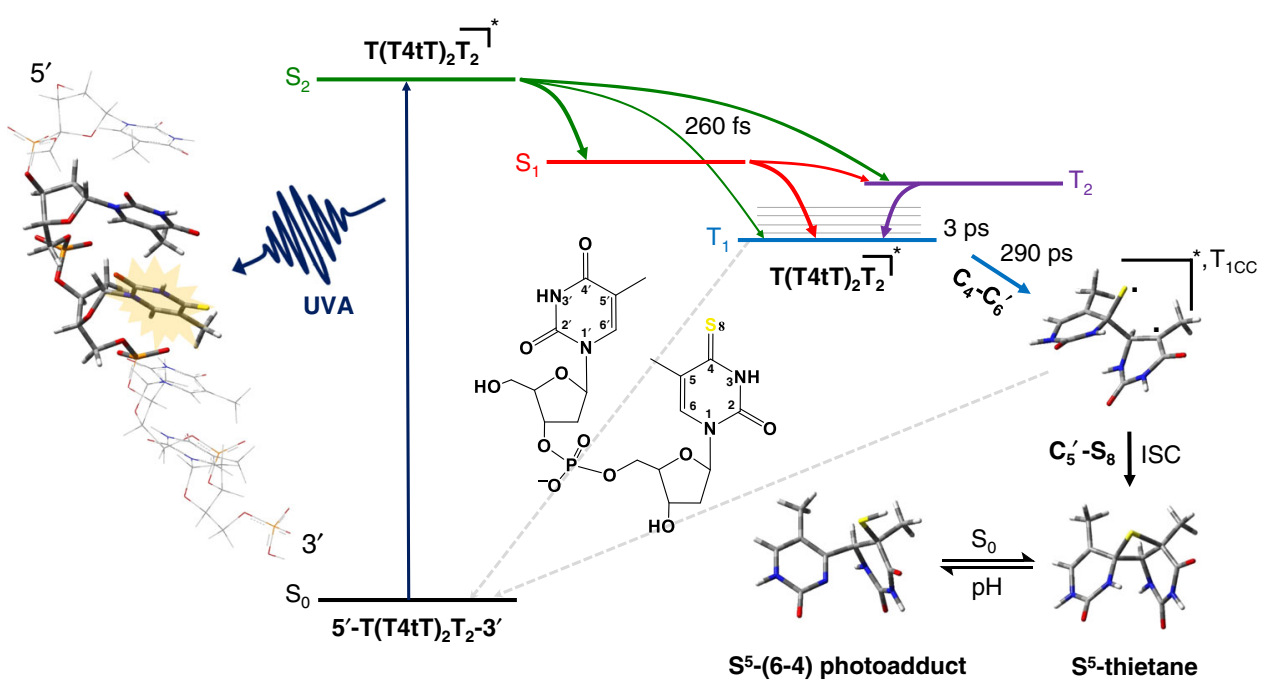

Fig. 6 Proposed mechanism for the formation of the DNA (6-4) photoadduct in PBS at pH 7.4. The colored arrows represent electronic transitions. A 4tT base is highlighted with light orange in the single-stranded DNA sequence depicted to the left to imply that $4 \mathrm{tT}$ bases are selectively photoactivated by the UVA radiation. $4 \mathrm{tT}$ and the thymidine $5^{\prime}$ relative to the $4 \mathrm{tT}$ are represented as tube in the single-stranded DNA sequence, while the other nucleobases are depicted as wireframe in order to highlight the importance of having a thymine $5^{\prime}$ relative to the $4 \mathrm{tT}$ for the reaction to occur. In the chemical structures yellow, red, blue, gray, and white, represent sulfur, oxygen, nitrogen, carbon, and hydrogen, respectively.

labeled $\mathrm{T}_{1 \mathrm{CC}}$, where the subscript $\mathrm{CC}$ refers to the formation of a covalent bond between $\mathrm{C} 4-\mathrm{C}^{\prime}$ atoms (see Fig. 6) ${ }^{23}$. Note that the $\mathrm{C}^{5}$ '-S8 bond of $\mathrm{T}_{1 \mathrm{CC}}$ remains broken, but with a weak interaction represented in Fig. 6 by two unpaired electrons. A $S_{0} / T_{1 c c}$ crossing point was calculated at the QM(CASSCF)//MM/6-31 G* level with a spin-orbit coupling constant of $32.6 \mathrm{~cm}^{-1}$, suggesting that this intersystem crossing pathway plays an important role in the subsequent $[2+2]$ cycloaddition reaction. According to Xie and $\mathrm{Cui}^{23}$, this reaction pathway can be divided into two phases. The first phase is a stepwise and adiabatic cycloaddition in the triplet state, while the second phase is a stepwise and nonadiabatic process between the triplet and the ground state of the thietane intermediate.

Using the nuclear coordinates reported by the authors ${ }^{23}$, we have calculated the absorption spectrum of the triplet minimum of the thietane $\left(\mathrm{T}_{1 \mathrm{CC}}\right)$ using TDDFT and including a reactionfield solvation model (IEFPCM) ${ }^{55}$ to take into consideration the dielectric effect of water in the vertical excitation energies. As shown in Supplementary Fig. 6, the absorption spectrum of the triplet minimum of the thietane intermediate exhibits two absorption bands with maxima around 362 and $442 \mathrm{~nm}$. The calculated absorption spectrum is in excellent agreement with the assignment of the increase in amplitude of the transientabsorption band in the spectral region from ca. 380 to $495 \mathrm{~nm}$ of panel e and f of Fig. 4 to the population of a triplet minimum of the thietane intermediate. The vertical excitation energies, the character of the electronic transitions, and their oscillator strengths are reported in Supplementary Table 1, whereas the Kohn-Sham orbitals are shown in Supplementary Fig. 7.

Supplementary Figs. 8 and 9 compare the normalized decay traces for $4 \mathrm{tT}$ and $\mathrm{T}(\mathrm{T} 4 \mathrm{tT})_{2} \mathrm{~T}_{2}$, respectively, at 430 and $550 \mathrm{~nm}$ probe wavelengths. As can be seen in those figures, there is a clear rise in the amplitude for $\mathrm{T}(\mathrm{T} 4 \mathrm{tT})_{2} \mathrm{~T}_{2}$ at $430 \mathrm{~nm}$ not observed in the monomer, while the triplet state of $4 \mathrm{tT}$ in the oligonucleotide at $550 \mathrm{~nm}$ decays with a faster lifetime than the triplet state of the $4 \mathrm{tT}$ monomer. These results lend support to the proposal that the absorption spectrum of the triplet minimum of the thietane overlaps with the absorption spectrum of a residual population of the triplet state of $4 \mathrm{tT}$ in the single-stranded oligonucleotide in the spectral region from ca. 380 to $495 \mathrm{~nm}$.
The question now arises as to how exactly the thietane intermediate is formed in the ground state? According to the calculations, there is a large energy barrier of ca. $30 \mathrm{kcal} \mathrm{mol}^{-1}$ to form the $\mathrm{C} 5^{\prime}-\mathrm{S} 8$ bond from the triplet minimum of the thietane $\mathrm{e}^{23}$. As mentioned above, this is consistent with the continuous increase in the amplitude of the transient-absorption signal at $430 \mathrm{~nm}$ observed Fig. $5 b$, suggesting that the $\mathrm{T}_{1 \mathrm{CC}}$ decays on a time delay longer than $3 \mathrm{~ns}$. Indeed, the calculations predict that the triplet state of the thietane intersystem crosses to the ground state near the $\mathrm{S}_{0} / \mathrm{T}_{1 \mathrm{cc}}$ intersection (spin-orbit coupling of $32.6 \mathrm{~cm}^{-1}$ ) to complete the cycloaddition reaction, as depicted in Fig. 6. The calculations predict a barrierless formation of the $\mathrm{C} 5^{\prime}-\mathrm{S} 8$ bond in the ground state, leading to the thietane formation ${ }^{23}$. The thietane intermediate in the ground state then rearranges through a concerted process with the simultaneous fission of the $\mathrm{C}_{4}-\mathrm{S}_{8}$ bond and the formation of the $\mathrm{S}_{8}-\mathrm{H}_{9}$ bond, leading to the formation of the (6-4) photoadduct ${ }^{23}$. The calculations suggest that the formation of the (6-4) photoadduct occurs with a relatively small energy barrier of $22 \mathrm{kcal} \mathrm{mol}^{-1}$ in the ground state 23 .

To provide experimental evidence that the (6-4) photoadduct is formed in $\mathrm{T}(\mathrm{T} 4 \mathrm{t} \mathrm{T})_{2} \mathrm{~T}_{2}$, we recorded the steady-state absorption and emission spectra for the $\mathrm{T}(\mathrm{T} 4 \mathrm{tT})_{2} \mathrm{~T}_{2}$ oligonucleotide before and after laser irradiation (Supplementary Fig. 4a), under equal conditions used for the transient-absorption experiments. The oligonucleotide was irradiated for $35 \mathrm{~min}$ at $342 \mathrm{~nm}$, equivalent to a $202 \mathrm{~J} \mathrm{~cm}^{-2}$ irradiation dose. After normalizing the absorption spectra at $334 \mathrm{~nm}$, where $4 \mathrm{tT}$ has its absorption maximum, the difference absorption spectrum reveals an absorption shoulder with maximum around $320 \mathrm{~nm}$, which is characteristic of the 5methyl-2-pyrimidone moiety in the (6-4) photoadduct $2,7,8,27,37$. The difference spectrum is also in good agreement with the absorption spectrum of the (6-4) photoadduct reported by Warren et al. ${ }^{37}$ in a double-stranded DNA oligonucleotide containing the T4tT sequence. Furthermore, excitation of the irradiated solution of the $\mathrm{T}(\mathrm{T} 4 \mathrm{tT})_{2} \mathrm{~T}_{2}$ oligonucleotide at $320 \mathrm{~nm}$ results in the emission spectrum shown in Supplementary Fig. 4c. The emission spectrum shows a band maximum at $390 \mathrm{~nm}$, which is consistent with the emission spectrum of (6-4) photoadduct reported previously ${ }^{37}$. In addition, the excitation spectrum collected near the maximum of the emission band at $390 \mathrm{~nm}$ is 
shown in Supplementary Fig. 4b. Within experimental uncertainties, it agrees with the shoulder observed in the difference absorption spectrum, as well as, with the absorption spectrum of (6-4) photoadduct ${ }^{37}$, supporting the idea that this photoadduct is formed under the experimental conditions used in our study.

Previous investigations have shown that the thietane intermediate is in equilibrium with the (6-4) photoadduct (Fig. 6) ${ }^{34,37}$, the former being the predominant species at neutral $\mathrm{pH}$. Importantly, the yield of the (6-4) photoadduct increases under basic conditions ${ }^{34}$. Hence, to provide further evidence for the formation of the (6-4) photoadduct in the $\mathrm{T}(\mathrm{T} 4 \mathrm{t} \mathrm{T})_{2} \mathrm{~T}_{2}$ oligonucleotide, we prepared buffered solutions of equal concentrations at $\mathrm{pH}$ of $6.2,7.4$, and 8.2 using the irradiated solution of the oligonucleotide at $\mathrm{pH} 7.4$, and measured their emission and excitation spectra. As shown in Supplementary Fig. 10, the emission spectrum increases with an increase in $\mathrm{pH}$, while the excitation spectrum of all three solutions exhibits a maximum at $320 \mathrm{~nm}$, in good agreement with the absorption spectrum of (6-4) photoadduct ${ }^{37}$. Collectively, the experimental results reported in this study and the QM(CASPT2//CASSCF)/MM calculations reported by $\mathrm{Xie}$ and $\mathrm{Cui}^{23}$ demonstrate that the thietane intermediate, which originates from the initial triplet state population of $4 \mathrm{tT}$ in the single-stranded DNA oligonucleotide, is the key intermediate in the formation of (6-4) photoadduct. Therefore, our experimental results support the idea that the (6-4) photoadduct may be formed from the triplet state between two adjacent thymine or uracil bases ${ }^{14,15,18,21}$, if the excited triplet state of thymine or uracil is populated upon UV excitation in natural DNA or RNA, respectively. Indeed, recent experimental results provide evidence of the population of the triplet state in both thymine and uracil monomers ${ }^{56-62}$, as well as in single-stranded thymine oligonucleotides ${ }^{2,59,63}$, upon excitation at $266 \mathrm{~nm}$. The low triplet yields reported for these natural systems may explain why CPD are formed in higher yields than (6-4) photoadducts ${ }^{3}$.

Previous experimental results demonstrate that $4 \mathrm{tT}$ acts as an effective triplet-energy transfer photosensitizer to molecular oxygen when photoactivated in its monomeric form, which was supported by the high quantum yield of singlet-oxygen generation of $42 \%$ under $\mathrm{O}_{2}$-saturated acetonitrile solution ${ }^{46,50}$. However, indirect measurements of the generation of reactive oxygen species have suggested that when $4 \mathrm{tT}$ is incorporated into DNA, negligible amounts of reactive oxygen species are generated ${ }^{27}$. In this study, we have measured the singlet-oxygen quantum yield directly for the single-stranded $\mathrm{T}(\mathrm{T} 4 \mathrm{tT})_{2} \mathrm{~T}_{2}$ DNA oligonucleotide, demonstrating a $88 \%$ lower singlet-oxygen yield for $\mathrm{T}(\mathrm{T} 4 \mathrm{tT})_{2} \mathrm{~T}_{2}$ compared to that for $4 \mathrm{t} \mathrm{T}$ under equal experimental conditions (Table 1). This result, together with the population of the triplet minimum of the thietane intermediate and the formation of the (6-4) photoadduct, establish that the primary photochemical mechanism of $4 \mathrm{tT}$ when incorporated into DNA is a $[2+2]$ cycloaddition reaction instead of energy transfer to molecular oxygen to generate singlet molecular oxygen and other reactive oxygen species. Importantly, the (6-4) photoadduct is also expected to act as a Trojan horse $\mathrm{e}^{7,8}$, potentially leading to the formation of secondary cyclobutane pyrimidine dimer or oxidatively-generated damage of neighbor bases in $4 \mathrm{tT}$ containing single- and double-stranded DNA.

In summary, this study presents the spectroscopic detection of a triplet-state minimum of the thietane intermediate, which intersystem crosses to populate the thietane intermediate in the ground state in a single-stranded DNA oligonucleotide. The timescale at which this triplet minimum is populated and the subsequent formation of the (6-4) photoadduct from the thietane intermediate in the ground state are determined. It further provides experimental evidence for the population of a triplet minimum of the thietane intermediate in a time delay as short as ca. 3 ps directly from the triplet state of $4 \mathrm{tT}$ in the $\mathrm{T}(\mathrm{T} 4 \mathrm{tT})_{2} \mathrm{~T}_{2}$ singlestranded DNA oligonucleotide. The thietane intermediate in the ground state rearranges to form the (6-4) photoadduct, as evidenced from the irradiation experiments and from the determination of the characteristic absorption and fluorescence-emission spectra of this photoproduct. For complete disclosure, our results do not imply (or rule out) that the (6-4) photoadduct in the natural DNA or RNA system may also be formed from a chargetransfer state or from an initial electron transfer event. All these pathways could compete among each other in the formation of the (6-4) photoadduct, depending on the specific conformations, the redox properties, and electronic structure properties of the particular system under investigation (i.e., dinucleotides or singleversus double-stranded oligonucleotides, etc.).

Equally important, our results provide alternative insights for the investigation and understanding of the photodimerization mechanisms in dimeric sequences in single- and double-stranded DNA oligonucleotides containing thiobase analogs, where base sequence, stacking, and pairing interactions are expected to play a paramount role in controlling their photochemistry ${ }^{50}$. Additional experiments are currently underway in our group to investigate this chemistry in single- and double-stranded oligonucleotides.

\section{Methods}

Materials and steady-state spectroscopy. 4-Thiothymidine (4tT, 99\% purity) was obtained from Carbosynth Limited, Berkshire, UK, and was used as received. The HPLC-purified and lyophilized DNA oligonucleotide was obtained from the KareBay Biochem., Inc. Note that the incorporation of only one $4 \mathrm{tT}$ in a singlestranded oligonucleotide should be sufficient to form the thietane and the (6-4) photoproduct. Our choice of using an oligonucleotide containing two 4tT bases was made strategically to increase the absorbance of the oligonucleotide at the excitation wavelength of $342 \mathrm{~nm}$ relative to the absorbance at ca. $260 \mathrm{~nm}$, where the thymine bases primarily absorb. This choice allows us to use less total amount oligonucleotide per experiment, and is also expected to increase the probability of thietane and (6-4) photoadduct formation, because up to two thietane could be formed per photoexcited oligonucleotide, hence, increasing the signal-to-noise ratio in the transient-absorption experiments.

Phosphate buffered saline (PBS) solutions with total phosphate concentration of $16 \mathrm{mM}$ were freshly prepared using $0.4933,0.4661$, and $0.5048 \mathrm{~g}$ of monobasic sodium phosphate and $0.0653,0.0961$, and $0.0505 \mathrm{~g}$ of dibasic sodium phosphate dissolved in $250 \mathrm{~mL}$ of ultrapure water to generate PBS solutions of 7.4, 6.2, and 8.2 , respectively. The $\mathrm{pH}$ was adjusted using $0.1 \mathrm{M}$ solutions of $\mathrm{NaOH}$ and $\mathrm{HCl}$. Steady-state absorption and emission spectroscopy were performed using a Cary 100 and Cary Eclipse spectrometers, respectively. Fluorescence spectra were taken at PMT voltage of $820 \mathrm{~V}$, with slit widths of $5 \mathrm{~nm}$, averaging time of $1 \mathrm{~s}$ and scan rate of $30 \mathrm{~nm} \mathrm{~min}^{-1}$

Singlet-oxygen phosphorescence measurements. Nanosecond time-resolved luminescence spectroscopy was used to determine the ${ }^{1} \mathrm{O}_{2}$ quantum yield $\left(\Phi_{\Delta}\right)$ for $\mathrm{T}(\mathrm{T} 4 \mathrm{tT})_{2} \mathrm{~T}_{2}$ and $4 \mathrm{tT}$ in TRIS-buffered $\mathrm{D}_{2} \mathrm{O}$ solution, under both air- and $\mathrm{O}_{2}$ saturated conditions. A Spectra Physics GCR-150-30 Nd:YAG laser $(355 \mathrm{~nm}, 7 \mathrm{~ns}$ pulse width) was used as the excitation source. Singlet-oxygen phosphorescence decay traces were collected at $1270 \mathrm{~nm}$ using a modified Fluorolog-3 spectrometer (HORIBA, Jobin Yvon) with a NIR sensitive photomultiplier tube (H10330A-45, Hamamatsu) and stored on a digital oscilloscope (TDS 360, Tektronics). Solutions of $\mathrm{T}(\mathrm{T} 4 \mathrm{tT})_{2} \mathrm{~T}_{2}, 4 \mathrm{tT}$, and the phenalenone standard were prepared in Tris-buffered $\mathrm{D}_{2} \mathrm{O}$ with matching absorbance of 0.3 at $355 \mathrm{~nm}$ in $1 \times 1 \mathrm{~cm}$ path length quartz cuvettes. The $\mathrm{O}_{2}$-saturated solutions were bubbled with molecular oxygen for $20 \mathrm{~min}$. The photodegradation of the sample was not allowed to reach more than $3 \%$, as judged using UV-vis spectroscopy. The quantum yields were determined in back-to-back luminescence experiments of $\mathrm{T}(\mathrm{T} 4 \mathrm{t} \mathrm{T})_{2} \mathrm{~T}_{2}, 4 \mathrm{tT}$, and phenalenone solutions under equal conditions, using the reported $\Phi_{\Delta}$ for phenalenone $\left(\Phi_{\Delta}=\right.$ $0.98)^{52}$.

Ultrafast broadband transient-absorption spectroscopy. The broadband transient-absorption spectrophotometer made use of a Ti:Sapphire oscillator (Vitesse, Coherent, Santa Clara, CA, USA) that seeds a regenerative amplifier (Coherent Libra-HE) generating $100 \mathrm{fs}$ pulses at $800 \mathrm{~nm}$ with a repetition rate of $1 \mathrm{kHz}$. The fundamental beam is used to pump a Traveling Optical Parametric Amplifier of Superfluorescence (TOPAS, Quantronix/Light Conversion, Vilnius, Lithuania), which in this work, was tuned to $342 \mathrm{~nm}$. A translating $2 \mathrm{~mm} \mathrm{CaF}$ crystal was used to generate the white light continuum for probing. The absorbance of the oligonucleotide solution at the excitation wavelength of $342 \mathrm{~nm}$ was $\sim 1.2$, 
while that of the $4 \mathrm{tT}$ monomer was 0.7 . A 2 -mm optical cell was used. The solutions were stirred continuously with a Teflon-coated magnetic stirrer. All solutions were kept below $10 \%$ photodegradation, as evaluated using UV-vis spectroscopy at the lowest-energy absorption band. Data processing made use of a home-made LabView program, while the target and global analyses were performed using the Glotaran software ${ }^{64,65}$. The decay traces obtained from the femtosecond transient-absorption data were globally fitted using a four-component sequential kinetic model, in conjunction with a coherent spectral fitting component to model the stimulated Raman emission, convoluted with a Gaussian instrument response function of $200 \pm 50 \mathrm{fs}$ (FWHM). The fourth kinetic component required a large lifetime (i.e., $>3$ ns) to fit the long-lived transient signals satisfactorily for both the oligonucleotide and the monomer, with the assumption that the long-lived signal decay exponentially.

Determination of relative quantum yields. Equation 1 was used to estimated the relative quantum yield of the triplet minimum of the thietane intermediate using the amplitudes from the global fit analysis (i.e., taken from the EADS) at the probe wavelength of $430 \mathrm{~nm}$, as follows:

$$
\text { relative \% quantum yield }=\frac{\left|A_{n}\right|}{\left|A_{1}\right|+\left|A_{2}\right|+\left|A_{3}\right|+\left|A_{4}\right|} \times 100,
$$

where $A_{n}$ are the amplitudes associated with the population of the triplet-state minimum of the thietane $\left(A_{3}+A_{4}\right)$ and the other amplitudes are associated with stimulated emission, triplet-state absorption and residual triplet-state absorption. Note that we used $A_{3}(430 \mathrm{~nm})+A_{4}(430 \mathrm{~nm})$ because both amplitudes contribute to the rise of the absorption band of the triplet minimum of the thietane at $430 \mathrm{~nm}$ during the second and third lifetimes, as can be observed in Supplementary Fig. $2 \mathrm{~b}$. Using this methodology, an average quantum yield value of $25 \pm 5 \%$ was determined from two independent transient-absorption measurements. Note that this value should be considered as an upper limit because the triplet state of the $4 \mathrm{tT}$ in the oligonucleotide also absorbs at this probe wavelength. The reported uncertainty is twice the standard deviation.

Equation 1 was also used to estimate the fraction of the triplet state of $4 \mathrm{tT}$ that decays by self-quenching back to the ground state in the monomer at the probe wavelength of $550 \mathrm{~nm}$, using the $A_{3}(550 \mathrm{~nm})$ as the nominator $(30 \pm 5 \%)$.

Density functional theory calculations. All computations were performed using Gaussian 16 suite of programs ${ }^{66}$. The absorption spectrum of the triple-state minimum of the thietane and the thietane intermediate in the ground state were calculated using two different functionals, M052X and $\omega \mathrm{B} 97 \mathrm{XD}$, and the 6-311+ $+\mathrm{G}(\mathrm{d}, \mathrm{p})$ standard basis set. The absorption spectrum, and the vertical excitation energies and oscillator strengths of $\mathrm{T}_{1 \mathrm{CC}}$ thietane triplet minimum, where calculated using the unrestricted $\omega$ B97XD functional and are reported in Supplementary Fig. 11 and Supplementary Table 2 for completeness. The optimized structures were taken from the work of Xie et al. ${ }^{23}$. Bulk solvent effects were modeled by using the integral equation formalism version of the polarizable continuum model ${ }^{55}$.

\section{Data availability}

The data supporting the findings of this study are available within the article and in its Supplementary Information. Additional data are available from the corresponding author upon reasonable request.

\section{Code availability}

The software used in this study for global and target analyses is freely available at http:// glotaran.org/.

Received: 30 July 2019; Accepted: 15 June 2020;

Published online: 17 July 2020

\section{References}

1. Cadet, J., Mouret, S., Ravanat, J. L. \& Douki, T. Photoinduced damage to cellular DNA: direct and photosensitized reactions. Photochem. Photobiol. 88, 1048-1065 (2012).

2. Schreier, W. J., Gilch, P. \& Zinth, W. Early events of DNA photodamage. Annu. Rev. Phys. Chem. 66, 497-519 (2015).

3. Cadet, J. \& Vigny, P. in Bioorganic Photochemistry, Vol. 1 (ed. Morrison, H.) 1-272 (Wiley-Interscience, 1990).

4. Ruzsicska, B. P. \& Lemaire, D. G. E. in CRC Handbook of Organic Photochemistry and Photobiology (eds. Horspool, W. M. \& Song, P.-S.) 1289-1317 (CRC Press, 1995).

5. Ravanat, J.-L., Douki, T. \& Cadet, J. Direct and indirect effects of UV radiation on DNA and its components. J. Photochem. Photobiol. B 63, 88-102 (2001).
6. Melnikova, V. O. \& Ananthaswamy, H. N. Cellular and molecular events leading to the development of skin cancer. Mutat. Res. 571, 91-106 (2005).

7. Vendrell-Criado, V., Rodrígues-Muñiz, G. M., Cuquerella, M. C., LhiaubetVallet, V. \& Miranda, M. A. Photosensitization of DNA by 5-methyl-2pyrimidone deoxyribonucleoside: (6-4) photoproduct as a possible Trojan hourse. Angew. Chem. Int. Ed. 125, 6604-6607 (2013).

8. Vendrell-Criado, V., Rodrígues-Muñiz, G. M., Lhiaubet-Vallet, V., Cuquerella M. C. \& Miranda, M. A. The (6-4) dimeric lesion as a DNA photosensitizer. ChemPhysChem 17, 1979-1982 (2016).

9. Haiser, K. et al. Mechanism of UV-induced formation of Dewar lesions in DNA. Angew. Chem. Int. Ed. 51, 408-411 (2012).

10. Marguet, S. \& Markovitsi, D. Time-resolved study of thymine dimer formation. J. Am. Chem. Soc. 127, 5780-5781 (2005).

11. Lemaire, D. G. E. \& Ruzsicska, B. P. Quantum yields and secondary photoreactions of the photoproducts of dTpdT, dTpdC and dTpdU. Photochem. Photobiol. 57, 755-769 (1993).

12. Blancafort, L. \& Migani, A. Modeling thymine photodimerizations in DNA: mechanism and correlation diagrams. J. Am. Chem. Soc. 129, 14540-14541 (2007).

13. Ai, Y.-J., Liao, R.-Z., Chen, S.-F., Luo, Y. \& Fang, W.-H. Theoretical studies on photoisomerizations of (6-4) and Dewar photolesions in DNA. J. Phys. Chem. B 114, 14096-14102 (2010).

14. Yang, Z. B., Eriksson, L. A. \& Zhang, R. B. A theoretical rationale for why azetidine has a faster rate of formation than oxetane in $\mathrm{TC}(6-4)$ photoproducts. J. Phys. Chem. B 115, 9681-9686 (2011).

15. Yang, Z. B., Zhang, R. B. \& Erickson, L. A. A triplet mechanism for the formation of thymine-thymine (6-4) dimers in UV-irradiated DNA. Phys. Chem. Chem. Phys. 13, 8961-8966 (2011).

16. Middleton, C. T. et al. DNA excited-state dynamics: from single bases to the double helix. Annu. Rev. Phys. Chem. 60, 217-239 (2009).

17. Banyasz, A. et al. Electronic excited states responsible for dimer formation upon UV absorption directly by thymine strands: joint experimental and theoretical study. J. Am. Chem. Soc. 134, 14834-14845 (2012).

18. Giussani, A., Serrano-Andrés, L., Merchán, M., Roca-Sanjuán, D. \& Garavelli, M. Photoionduced formation mechanism of the thymine-thymine (6-4) adduct. J. Phys. Chem. B 117, 1999-2004 (2013).

19. Conti, I. et al. Multiple electronic and structural factors control cuclobutane pyrimidine dimer and 6-4 thymine-thymine photodimerization in a DNA duplex. Chem. Eur. J. 23, 15177-15188 (2017)

20. Giussani, A., Conti, I., Nenov, A. \& Garavelli, M. Photoionduced formation mechanism of the thymine-thymine (6-4) adduct in DNA: a QM(CASPT2// CASSCF):MM(AMBER) study. Faraday Discuss. 207, 375-387 (2018).

21. Wang, X. \& Yu, H. The effect of DNA backbone on the triplet mechanism of UV-induced thymine-thymine (6-4) dimer formation. J. Mol. Model. 24, 319 (2018).

22. Wang, S. Y. Photochemistry and Photobiology of Nucleic Acids. Vol. 1 (Academic Press, 1976).

23. Xie, B.-B. \& Cui, C.-X. Theoretical studies on photo-induced cycloaddition and (6-4) reactions of the thymidine:4-thiothymidine dimer in a DNA duplex. Phys. Chem. Chem. Phys. 21, 2006-2016 (2019).

24. Milder, S. J. \& Kliger, D. S. Spectroscopy and photochemistry of thiouracils: implications for the mechanism of photocrosslinking in tRNA. J. Am. Chem. Soc. 107, 7365-7373 (1985).

25. Favre, A. in Bioorganic Photochemistry (ed. Morrison, H.) 379-425 (J. Wiley \& Sons, 1990).

26. Favre, A., Saintomé, C., Fourrey, J.-L., Clivio, P. \& Laugâa, P. Thionucleobases as intrinsic photoaffinity probes of nucleic acid structure and nucleic acidprotein interactions. J. Photochem. Photobiol. B 42, 109-124 (1998).

27. Reelfs, O. et al. Identification of potentially cytotoxic lesions induced by UVA photoactivation of DNA 4-thiothymidine in human cells. Nucleic Acids Res. 39, 9620 (2011).

28. Wang, S. Y. in Photochemistry and Photobiology of Nucleic Acids, Vol. 1 (ed. Wang, S. Y.) 295-356 (Academic Press, 1976).

29. Improta, R. Photophysics and photochemistry of thymine deoxy-dinucleotide in water: a PCM/TD-DFT quantum mechanical study. J. Phys. Chem. B 116, 14261-14274 (2012).

30. Esposito, L. et al. Effect of C5-methylation of cytosine on the photoreactivity of DNA: a joint experimental and computational study of TCG trinucleotides. J. Am. Chem. Soc. 136, 10838-10841 (2014).

31. Banyasz, A. et al. Effect of C5-methylation of cytosine on the UV-induced reactivity of duplex DNA: conformational and electronic factors. J. Phys. Chem. B 120, 4232-4242 (2016).

32. Markovitsi, D. UV-induced DNA damage: the role of electronic excited states. Photochem. Photobiol. 92, 45-51 (2016).

33. Jian, Y. et al. Indications of 5' to 3' interbase electron transfer as the first step of pyrimidine dimer formation probed by a dinucleotide analog. Chem. Eur. J. 23, 7526-7537 (2017). 
34. Clivio, P., Fourrey, J. L., Gasche, J. \& Favre, A. DNA photodamage mechanistic studies: characterization of a thietane intermediate in a model reaction relevant to "6-4 lesions". J. Am. Chem. Soc. 113, 5481-5483 (1991).

35. Clivio, P., Fourrey, J.-L., Gasche, J. \& Favre, A. Novel insight into the stereochemical pathway leading to (6-4) pyrimidine-pyrimidinone photoproducts in DNA. Tetrahedron Lett. 33, 1615-1618 (1992).

36. Liu, J. \& Taylor, J.-S. Remarkable photoreversal of a thio analog of the Dewar valence isomer of the (6-4) photoproduct of DNA to the parent nucleotides. J. Am. Chem. Soc. 118, 3287-3288 (1996).

37. Warren, M. A., Murray, J. B. \& Connolly, B. A. Synthesis and characterization of oligodeoxynucleotides containing thio analogues of (6-4) pyrimidinepyrimidinone photo-dimers. J. Mol. Biol. 279, 89-100 (1998)

38. Brem, R., Guven, M. \& Karran, P. Oxidatively-generated damage to DNA and proteins mediated by photosensitized UVA. Free Radic. Biol. Med. 107, 101-109 (2017).

39. Liu, J. \& Taylor, J.-S. Templete-directed photoligation of oligodeoxyribonucleotides via 4-thiothymidine. Nucleic Acids Res 26, 3300-3304 (1998).

40. Favre, A. \& Thomas, G. Transfer RNA: from photophysics to photobiology. Annu. Rev. Biophys. Bioeng. 10, 175-195 (1981).

41. Favre, A. \& Fourrey, J.-L. Structural probing of small endonucleolytic ribozymes in solution using thio-substituted nucleobases as intrinsic photolabels. Acc. Chem. Res. 28, 375-382 (1995).

42. Harada, Y., Suzuki, T., Ichimura, T. \& Xu, Y.-Z. Triplet formation of 4thiothimidine and its photosensitization to oxygen studied by time-resolved thermal lensing technique. J. Phys. Chem. B 111, 5518-5524 (2007).

43. Harada, Y. et al. Ultrafast intersystem crossing of 4-thiothymidine in aqueous solution. J. Phys. Chem. Lett. 1, 480-484 (2010).

44. Reichardt, C. \& Crespo-Hernández, C. E. Room-temperature phosphorescence of the DNA monomer analogue 4-thiothymidine in aqueous solution after UVA excitation. J. Phys. Chem. Lett. 1, 2239-2243 (2010).

45. Reichardt, C. \& Crespo-Hernández, C. E. Ultrafast spin crossover in 4thiothymidine in an ionic liquid. Chem. Commun. 46, 5963-5965 (2010).

46. Pollum, M., Jockusch, S. \& Crespo-Hernández, C. E. 2,4-Dithiothymine as a potent UVA chemotherapeutic agent. J. Am. Chem. Soc. 136, 17930-17933 (2014).

47. Pollum, M., Martínez-Fernández, L. \& Crespo-Hernández, C. E. in Photoinduced Phenomena in Nucleic Acids I, Vol. 355 (eds Barbatti, M., Borin, A. C. \& Ullrich, S.) 245-327 (Springer, 2015).

48. Martínez-Fernández, L. et al. Decoding the molecular basis for the population mechanism of the triplet phototoxic precursors in UVA light-activated pyrimidine anticancer drugs. Chem. Eur. J. 23, 2619-2627 (2017).

49. Borrego-Varillas, R. et al. Observation of the sub-100 femtosecond population of a dark state in a thiobase mediating intersystem crossing. J. Am. Chem. Soc. 140, 16087-16093 (2018).

50. Ashwood, A., Pollum, M. \& Crespo-Hernández, C. E. Photochemical and photodynamical properties of sulfur-substituted nucleic acid bases. Photochem. Photobiol. 95, 33-58 (2019).

51. Cui, G. \& Thiel, W. Intersystem crossing enables 4-thiothymidine to act as a photosensitizer in photodynamic therapy: an ab initio QM/MM study. J. Phys. Chem. Lett. 5, 2682-2687 (2014).

52. Schmidt, R., Tanielian, C., Dunsbach, R. \& Wolff, C. Phenalenone, a universal reference compound for the determination of quantum yields of singlet oxygen $\mathrm{O}_{2}\left({ }^{1} \Delta_{\mathrm{g}}\right)$ sensitization. J. Photochem. Photobiol. A 79, 11-17 (1994).

53. Reichardt, C., Wen, C., Vogt, R. \& Crespo-Hernández, C. Role of intersystem crossing in the fluorescence quenching of 2-aminopurine 2'-deoxyriboside in solution. Photochem. Photobiol. Sci. 12, 1341-1350 (2013).

54. Reichardt, C., Vogt, R. A. \& Crespo-Hernández, C. E. On the origin of ultrafast nonradiative transitions in nitro-polycyclic aromatic hydrocarbons: excited-state dynamics in 1-nitronaphthalene. J. Chem. Phys. 131, 224518 (2009).

55. Cancès, E., Mennucci, B. \& Tomasi, J. A new integral equation formalism for the polarizable continuum model: theoretical background and applications to isotropic and anisotropic dielectrics. J. Chem. Phys. 107, 3032-3041 (1997).

56. Hare, P. M., Crespo-Hernández, C. E. \& Kohler, B. Solvent-dependent photophysics of 1-cyclohexyluracil: ultrafast branching in the initial bright state leads nonradiatively to the electronic ground state and a long-lived ${ }^{1} \mathrm{np}^{*}$ state. J. Phys. Chem. B 110, 18641-18650 (2006).

57. Hare, P. M., Crespo-Hernández, C. E. \& Kohler, B. Internal conversion to the electronic ground state occurs via two distinct pathways for pyrimidine bases in aqueous solution. Proc. Natl. Acad. Sci. USA 104, 435-440 (2007).
58. Hare, P. M., Middleton, C. T., Mertel, K. I., Herbert, J. M. \& Kohler, B. Timeresolved infrared spectroscopy of the lowest triplet state of thymine and thymidine. Chem. Phys. 347, 383-392 (2008).

59. Kwok, W.-M., Ma, C. \& Phillips, D. L. A doorway state leads to photostability or triplet photodamage in thymine DNA. J. Am. Chem. Soc. 130, 5131-5139 (2008).

60. Brister, M. M. \& Crespo-Hernández, C. E. Direct observation of triplet-state population dynamics in the RNA uracil derivative 1-cyclohexyluracil. J. Phys. Chem. Lett. 6, 4404-4409 (2015).

61. Pilles, B. M. et al. Decay pathways of thymine revisited. J. Phys. Chem. A 122, 4819-4828 (2018).

62. Brister, M. M. \& Crespo-Hernández, C. E. Excited-state dynamics in the RNA nucleotide uridine 5'-monophosphate investigated using femtosecond broadband transient absorption spectroscopy. J. Phys. Chem. Lett. 10, 2156-2161 (2019).

63. Pilles, B. M. et al. Mechanism of the decay of thymine triplets in DNA single strands. J. Phys. Chem. Lett. 5, 1616-1622 (2014).

64. Snellenburg, J. J., Laptenok, S. P., Seger, R., Mullen, K. M. \& Stokkum, I. H. Glotaran: a Java-based graphical user interface for the R package TIMP. J. Stat. Softw. 49, 1-22 (2012).

65. van Stokkum, I. H. M., Larsen, D. S. \& van Grondelle, R. Global and target analysis of time-resolved spectra. Biochim. Biophys. Acta 1657, 82-104 (2004).

66. Frisch, M. J. et al. Gaussian 16 (Revision B.01) (Gaussian, Inc., Wallingford CT, Pittsburgh, PA, 2016).

\section{Acknowledgements}

The authors acknowledge the National Science Foundation (Grant No. CHE-1800052) They also thank Mr. Brennan Ashwood for performing preliminary analysis of the transient-absorption data collected in earlier experiments. C.R. thanks the Deutsche Forschungsgemeinschaft (DFG) for support. This work made use of the High Performance Computing Resource in the Core Facility for Advanced Research Computing at CWRU.

\section{Author contributions}

C.E.C.-H. conceived and designed the experiments; L.A.O.-R., C.R., S. H., and S.J. performed the experiments; L.A.O.-R., S. H., and S.J. analyzed the data; C.E.C.-H. and S.J contributed reagents/materials/analysis tools; L.A.O.-R. and C.E.C.-H. wrote the paper All authors read and approved the final version of the paper.

\section{Competing interests}

The authors declare no competing interests.

\section{Additional information}

Supplementary information is available for this paper at https://doi.org/10.1038/s41467 020-17333-y.

Correspondence and requests for materials should be addressed to C.E.C.-H.

Peer review information Nature Communications thanks Virginie Lhiaubet, Massimo Olivucci and the other, anonymous, reviewer for their contribution to the peer review of this work. Peer reviewer reports are available.

Reprints and permission information is available at http://www.nature.com/reprints

Publisher's note Springer Nature remains neutral with regard to jurisdictional claims in published maps and institutional affiliations.

\footnotetext{
Open Access This article is licensed under a Creative Commons Attribution 4.0 International License, which permits use, sharing, adaptation, distribution and reproduction in any medium or format, as long as you give appropriate credit to the original author(s) and the source, provide a link to the Creative Commons license, and indicate if changes were made. The images or other third party material in this article are included in the article's Creative Commons license, unless indicated otherwise in a credit line to the material. If material is not included in the article's Creative Commons license and your intended use is not permitted by statutory regulation or exceeds the permitted use, you will need to obtain permission directly from the copyright holder. To view a copy of this license, visit http://creativecommons.org/ licenses/by/4.0/.
}

(c) The Author(s) 2020 